\title{
A Light-Deprivation Mouse Model Potentially for Studying the Complete Congenital Stationary Night Blindness
}

\author{
Chanyi Lu',2*, Qiqin Li1,2,3*, Yaoyao Li1,2*, Yun Wang1,2,4\#, Yun-Feng Zhang1,2\# \\ ${ }^{1}$ School of Ophthalmology and Optometry, Eye Hospital, Wenzhou Medical University, Wenzhou, China \\ ${ }^{2}$ State Key Laboratory Cultivation Base and Key Laboratory of Vision Science, Ministry of Health of the People's \\ Republic of China, Zhejiang Provincial Key Laboratory of Ophthalmology and Optometry, Wenzhou, China \\ ${ }^{3}$ Lu'an People's Hospital, Lu'an, China \\ ${ }^{4}$ Allen Institute for Brain Science, Seattle, WA, USA \\ Email: "yun.wang@mail.eye.ac.cn, "wangy62@gmail.com,"
}

Received 11 April 2016; accepted 3 June 2016; published 6 June 2016

Copyright (C) 2016 by authors and Scientific Research Publishing Inc.

This work is licensed under the Creative Commons Attribution International License (CC BY).

http://creativecommons.org/licenses/by/4.0/

(c) (i) Open Access

\begin{abstract}
Current rodent models of the complete congenital stationary night blindness (CSNB1) were timeconsuming in breeding and validation, which makes it imperative to find a more "easily handle" animal model to broaden our understanding of this disorder. In the present study, a light-deprivation (LD) mouse model was made to validate whether it was a more "suitable" animal mode for investigating the pathogenesis of the CSNB1. Compared with controls, the LD mice exhibited a remarkable reduction in the amplitude of the dark-adapted electroretinogram (ERG) b-wave, the Max-ERG b-wave and also the oscillatory potentials (Ops), indicating an abnormal activity of rod bipolar cells in the retina. However, the ERG a-wave was relatively normal in the LD mice, which was quite consistent with what was confirmed in previously reported animal models of the CSNB1 and CSNB patients. Taken together, the LD mouse model showed CSNB1-like negative ERG responses as evidenced by the abnormal $b$-wave. Our study will provide a potentially useful animal model to decipher the pathogenesis of the CSNB1.
\end{abstract}

\section{Keywords}

Complete Congenital Stationary Night Blindness, Light-Deprivation, Electroretinogram, Oscillatory Potentials

\footnotetext{
*These authors contributed equally to this work.

\#Corresponding authors.
}

How to cite this paper: Lu, C.Y., Li, Q.Q., Li, Y.Y., Wang, Y. and Zhang, Y.-F. (2016) A Light-Deprivation Mouse Model Potentially for Studying the Complete Congenital Stationary Night Blindness. World Journal of Neuroscience, 6, 181-183. 
The congenital stationary night blindness (CSNB) is a non-progressive disorder of the retina characterized by loss of night vision [1], which could be sub-classified as complete CSNB (CSNB1) and incomplete CSNB (CSNB2) [2]. The CSNB1 is a human disorder in which patients have a profound loss of rod-mediated visual sensitivity. The rodent model for this disorder was mainly the X-linked [3]-[6]. However, more or less, these rodent models were time-consuming in breeding and validation, which makes it imperative to find a more "easily handle" animal model to broaden our understanding of the CSNB1. In the present study, we made a light-deprivation (LD) mouse model to validate whether it was a more "suitable" animal mode for investigating the pathogenesis of the CSNB1. Basically, neonatal ICR mice were housed either in a 12/12 h light-dark cycle (the control group) or in a complete darkness (the LD group) since birth (P0) for three weeks, and then used for electroretinogram (ERG) recordings based on the methods described previously [4]. Mice used in the recordings were at postnatal days 25 to 30 (P25-P35).

A plenty variety of animal models emerge aiming to investigate the pathogenesis of the CSNB1. The ERG responses from the nob mouse model of CSNB1 showed a normal a-wave and a missing b-wave [4]. Moreover, a potential rat model of CSNB1 was characterized with a relatively normal a-wave and a markedly reduced bwave [3]. These studies indicate that abnormal scotopic response with a significant reduction or even missing b-wave is a typical characteristic of the possible animal model of the CSNB1. In the current work, compared with controls, the LD mice exhibited a remarkable reduction in the amplitude of the dark-adapted ERG b-wave roughly by $34 \%$ in response to a low intensity flash. In response to a high intensity stimulus, compared with controls, the LD mice had a remarkable decrease in the amplitude of the Max-ERG b-wave by about 39\%, and the oscillatorypotentials (Ops) by about 63\% (Table 1). These findings indicate an abnormal activity of rod bipolar cells in the retina [7] [8], which were supported by previous documents on the rat model of the CSNB1 [3] and CSNB patients [2] [9]. Under light adapted conditions, the cone ERGs of the LD mice to single flash or $30-\mathrm{Hz}$ stimuli showed a decreased tendency in amplitude, which is compatible with the findings in CSNB1 patients [3]. However, the ERG a-wave was relatively normal in the LD mice (Table 1), which was quite consistent with what was confirmed in previously reported animal models of the CSNB1 [3]-[4] and CSNB patients [2] [9]. Collectively, the LD mouse model showed CSNB1-like negative ERG responses as evidenced by the relatively normal a-wave and abnormal b-wave. Our ongoing anatomical and electrophysiological analyses also showed great changes in both neuronal morphology and neural microcircuitry in the cerebral cortex of the LD mice, which further suggests that the mouse model described here will also be another potential model for studying the CSNB1. Together, this LD mouse model, more or less, will be useful to broaden our understanding of CSNB1 and to evaluate the effectiveness of experimental therapies for this disorder.

\section{Acknowledgements}

This study was supported by the grants from the Natural Science Foundation of Zhejiang Province of China (No.

Table 1. Comparison in ERG implicit time and amplitude between the control and light-deprivation mice.

\begin{tabular}{cccccc}
\hline & & \multicolumn{2}{c}{ Implicit time $(\mathrm{ms})$} & \multicolumn{2}{c}{ Amplitude $(\mu \mathrm{V})$} \\
\hline Item & Wave & Control $(n=17)$ & $\begin{array}{c}\text { Light deprivation } \\
(n=15)\end{array}$ & $\begin{array}{c}\text { Control } \\
(n=17)\end{array}$ & $\begin{array}{c}\text { Light deprivation } \\
(n=15)\end{array}$ \\
\hline Scot-ERG & a & $23.82 \pm 1.41$ & $22.82 \pm 2.41$ & $7.99 \pm 1.56$ & $7.83 \pm 2.61$ \\
& b & $82.53 \pm 2.70$ & $87.55 \pm 2.48$ & $241.38 \pm 21.71$ & $158.88 \pm 20.35^{* *}$ \\
Max-ERG & a & $14.53 \pm 0.40$ & $16.73 \pm 0.47^{* *}$ & $175.58 \pm 14.24$ & $138.30 \pm 27.18$ \\
Ops & b & $36.47 \pm 3.12$ & $44.18 \pm 3.23$ & $441.65 \pm 37.43$ & $271.00 \pm 36.07^{* *}$ \\
Phot-ERG & P1 & $25.35 \pm 0.51$ & $25.64 \pm 0.74$ & $175.85 \pm 23.05$ & $65.05 \pm 11.10^{* * *}$ \\
& a & $15.86 \pm 0.93$ & $15.45 \pm 0.93$ & $11.07 \pm 1.94$ & $7.73 \pm 1.36$ \\
30-Hz-flicker & b & $43.50 \pm 1.40$ & $43.18 \pm 1.99$ & $86.18 \pm 10.70$ & $67.34 \pm 10.77$ \\
\hline
\end{tabular}

Values indicate mean \pm SE. Individual samples $t$-test. ${ }^{*} P<0.05,{ }^{* *} P<0.01,{ }^{* * *} P<0.001$. 
LQ14H120003), the National Natural Science Foundation for Young Scientists of China (No. 81301117), the Natural Science Foundation of China (No. 81470660), and the Wenzhou Science and Technology Plans (No. Y20140139). The research leading to these results has also received funding from the European Union Seventh Framework Programme (FP7/2007-2013) under grant agreement nº 604102 (HBP).

\section{References}

[1] Ripps, H. (1982) Night Blindness Revisited; from Man to Molecules. Investigative Ophthalmology \& Visual Science, 23, 588-609.

[2] Miyake, Y., Yagasaki, K., Horiguchi, M., Kawase, Y. and Kanda, T. (1986) Congenital Stationary Night Blindness with Negative Electroretinogram. A New Classification. Archives of Ophthalmology, 104, 1013-1020. http://dx.doi.org/10.1001/archopht.1986.01050190071042

[3] Zhang, Z., Gu, Y., Li, L., Long T., Guo, Q. and Shi L. (2003) A Potential Spontaneous Rat Model of X-Linked Congenital Stationary Night Blindness. Documenta Ophthalmologica, 107, 53-57. http://dx.doi.org/10.1023/A:1024487912791

[4] Pardue, M.T., McCall, M.A., LaVail, M.M., Gregg, R. and Peachey, N.S. (1998) A Naturally Occurring Mouse Model of X-Linked Congenital Stationary Night Blindness. Investigative Ophthalmology \& Visual Science, 39, 2443-2449.

[5] Pardue, M.T., Ball, S.L., Mukhopadhyay, Candille, S.I., McCall, M.A., Gregg, R.G. and Peachey, N.S. (2001) nob: A Mouse Model of CSNB1. In: Anderson, R.E., LaVail, M.M. and Hollyfield, J.G., Eds., New Insights into Retinal Degenerative Diseases, Plenum Press, New York, 319-326. http://dx.doi.org/10.1007/978-1-4615-1355-1_34

[6] Gregg, R.G., Candille, S.I., Ball, S.L., Pardue, M.T. and Mccall, M.A. (2003) Identification of the Gene and the Mutation Responsible for the Mouse nob Phenotype. Investigative Ophthalmology \& Visual Science, 44, 378-384. http://dx.doi.org/10.1167/iovs.02-0501

[7] Robson, J.G. and Frishman, L.J. (1995) Response Linerarity and Kibectics of the Cat Retina: The Bipolar Cell Component of the Dark-Adapted Electroretinogram. Visual Neuroscience, 12, 837-850. http://dx.doi.org/10.1017/S0952523800009408

[8] Hood, D.C. and Birch, D.G. (1996) B Wave of the Scotopic (Rod) Electroretinogram as a Measure of the Activity of Human On-Bipolar Cells. Journal of the Optical Society of America A, 13, 623-633. http://dx.doi.org/10.1364/JOSAA.13.000623

[9] Al Oreany, A.A., Al Hadlaq, A. and Schatz, P. (2016) Congenital Stationary Night Blindness with Hypoplastic Discs, Negative Electroretinogram and Thinning of the Inner Nuclear Layer. Graefe's Archive for Clinical and Experimental Ophthalmology, 1-6. 